FACULDADE DE CIÊ NCIAS ECONÔ MICAS DA UFRGS

REESTRUTURAÇÁ O DA PRODUÇÁ O AGRICOLA NO RIO GRANDE DO SUL, DE 1970 A 1996 E UMA ESTIMAÇȦ O PARA 2012 TIAGO WICKSTROM ALVES

A CRIMINALIDADE NA RECIAO METROPOLTANA DE SALVADOR JOSÉ CARRERA FERNANDEZ, LUIZ FERNANDO LOBO

COMPEIITIVIDADE INTERNACIONAL EM SOFTWARE: UM ESTUDO SOBRE A EXPERIÊNCIA DE FLORIANÓ POLIS HOVÉDO NUNES LINS

MODELOS DE ORGANIZAÇẢ O E REPARTIÇẢ O DE RENDAS NA CADEIA PRODUTIVA DO GÁS NATURAL.

HELder QUEIROZ PINTO Jú NIOR, RODOLFO TORRES dOS SANTOS

REGIMES MONETÁ RIOS E DIVIDA PÚ BLICA: UMA ANÁ LISE DE MECANISMOS ALTERNATIVOS DE COORDENAÇÃO MACROECONÓ MICA

manoel Carlos de Castro Pires

ECONOMIA DOS RECURSOS NATURAIS E SEUS INDICADORES DE ESCASSEZ: UMA QUESTÃ O DE SUSTENTABILIDADE ANDREA SALES SOARES DE AZEVEDO MELO

O ECOPROTECIONISMO AGRICOLA NA UNIĀ O EUROPEIA E SEUS POSSIVEIS IMPACTOS SOBRE A ECONOMIA BRASILEIRA Rodrigo daniel Feix, Clá udio R. Fóffano Vasconcelos

PADRÓ ES DE DESENVOLVIMENTO, FUNÇ Ó ES ESTATAIS E ENDIVIDAMENTO NO CAPITALISMO CONTEMPORÁNEO paulo Balanco, Eduardo Costa Pinto

A INTERNACIONALIZAÇÃO DO VAREJO A PARTIR DOS CASOS WAL-MART E CARREFOUR

Armando joảo dalla Costa

UMA ANÁ LISE ECONOMÉTRICA DO FUTEBOL BRASILEIRO ARI Francisco de Araujo JR, Clá udio D. SHIKIDA, LEONARDO M. MONASTERIO

O BRASIL E A ECONOMIA INTERNACIONAL: RECUPERAÇÃ O E DEFESA DA AUTONOMIA NACIONAL

RESENHA DE ALEXANDRE CÉ SAR CUNHA LEITE

REGIMES MONETÁ RIOS: TEORIA E A EXPERIÊNCIA DO REAL ResenHa de Fernando Ferrari Filho

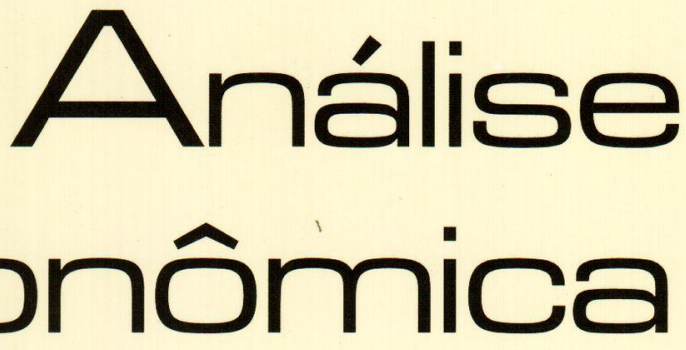


Universidade Federai. do Rio Grande do Sul Reitor: Prof José Carlos Ferraz Hemnemann

Facul dade de Cuéncias Economicas

Diretor: Prof. Gentil Corazza

Ceniro de Estudos f Prequisas Economicas

Diretor: Prof. Lovois de Andrade Miguel

Depariamenio de Crências Economicas

Chefe: Prof Ricardo Dathein

Departamento de Cîncias Coniábeis f A tuaria Chefe: Prof. Ceno Odilo Kops

Curso de Pós-Graduaçó em Economia

Coordenador: Prof. Fernando Ferrari Filho

Curso de Pos-Grainaça em Desenvolvimento RuRAI

Coordenador: Prof. Paulo Dabdab Waquil

Conseluo Eni tokial: André Moreira Cunha (UFRGS) Carlos G. A. Mielitz Netto (UFRGS), Carlos Henrique Hom (UFRGS). Eduardo A. Maldonado Filho (UFRGS). Eleutério F S. Prado (USP), Eugênio Lagemann (UFRGS), Fernando Cardim de Carvalho (UFRJ). Femando Ferrari Filho (UFRGS), Fernando de Holanda Barbosa (FGV/RJ), Flávio Augusto Ziegelmann (UFRGS), Flávio Vasconcellos Comin (UFRGS), Gentil Corazza (UFRGS), Giácomo Balbinot to Neto (UFRGS), Gustavo Franco (PUC/RJ) Hélio Henkin (UFRGS), Jan A. Kregel (UNCTAD), João Rogério Sanson (UFSC), Joaquim Pinto de Andrade (UnB), Júlio César Oliveira (UFRGS), Luiz Estrella Faria (UFRGS), Luiz Paulo Ferreira Nogueról (UFRGS), Marcelo S Portugal (UFRGS), Maria Alice Lahorgue (UFRGS), Octávio Augusto Camargo Conceicão (UFRGS), Paul Davidson (University of Tennessee), Paulo D. Waquil (UFRGS), Pedro C. D. Fonseca (UFRGS), Philip Arestis (University of Cambridge), Ricardo Dathein (UFRGS) Ronald Otto Hillbrecht (UFRGS), Sabino da Silva Porto Jr (UFRGS), Sérgio M. M. Monteiro (UFRGS), Stefano Florissi (UFRGS) e Werner Baer (University of IIIinois at Urbana - Champaign)

Comissão Emroniai: Eduardo Augusto Maldonado Filho, Fernando Ferrari Filho, Hélio Henkin. Marcelo Savino Portugal, Paulo Dabdab Waquil e Sérgio Marley Modesto Monteiro.

EnIrok: Sérgio Marley Modesto Monteiro

Ediror Adjun ro: Hélio Henkin

Secretário: Emerson Douglas Neves

REVISÃo DE IEX ros: Vanete Ricacheski

Emioração: Núcleo de Editoração e Criação da

Gráfica da UFRGS - Janaína Horn e Junia Saedt

Fundador: Prof Antonio Carlos Santos Rosa
Os materiais publicados na revista Análise Econômica são da exclusiva responsabilidade dos autores. É permitida a reprodução total ou parcial dos trabalhos, desde que seja citada a fonte. Aceita-se permuta com revistas congêneres. Aceitam-se, também, livros para divulgacão, elaboraça de resenhas e recensões Toda correspondência: material para publicação (vide normas na terceira capa), assinaturas e permutas devem ser dirigidos ao seguinte destinatário:

Prof. Sérgio Marley Modesto Monteiro Revista Andilse Económica - Av. João Pessoa, 52 CEP 90040-000 PORTO ALEGRE - RS, BRASIL Telefones: (051) $33163513 / 33164164$

Fax: (051) 33163990 - E-mail: rae@vortex ufrgs.br

A Revista Análise Econômica agradece a colaboração dos pareceristas do número 43, abaixo relacionados:

Adalmir Antonio Marquetti

André Moreira Cunha

Carlos José Caetano Bacha

Carlos Mielitz. Netto

Clailton Ataídes de Freitas

Claudio Roberto Fóffano Vasconcelos

Eduardo Ernesto Filippi

Eduardo Pontual Ribeiro

Eleuterio Fernando da Silva Prado

Fernando J Cardim de Carvalho

Fernando Augusto Mansor de Mattos

Fernando Ferrari Filho

Flávio Tosi Feijó

Flavio Vilela Vieira

Francisco Paulo Cipolla

Gentil Corazza

Gíacomo Balbinotto Neto

Helio Henkin

Jefferson Andronio Ramundo Staduto

João de Deus Sicsú Siqueira

José Carrera Fernandes

Leonardo Monteiro Monasterio

Luís Fernando de Paula

Luis Roberto Nascimento

Manoel Carlos de Castro Pires

Octavio Augusto Camargo Conceição

Patrízia Raggi Abdallah

Robson Antonio Grassi

Ronald Otto Hilbrech

Tiago Wickstrom Alves

Tito Belchior Silva Moreira

Análise Econônica

Ano 23, n ${ }^{\circ} 44$, setembro, 2005 - Porto Alegre

Faculdade de Ciências Economicas, UFRGS, 2000

Periodicidade semestral, março e setembro

1. Teoria Econômica - Desenvolvimento Regional -

Economia Agrícola - Pesquisa Teórica e Aplicada -

Periódicos. I.. Brasil

Faculdade de Ciências Econômicas,

Universidade Federal do Rio Grande do SuI

CDD 330.05

CDU $33(81)(05)$ 


\title{
Padrões de desenvolvimento, funções estatais e endividamento no capitalismo contemporâneo
}

\author{
Paulo Balanco** \\ Eduardo Costa Pinto"**
}

\begin{abstract}
Resumo: Este artigo discute as transformações do capitalismo no século XX adotando como roteiro teórico o conceito de ciclo econômico, no qual estão inscritas as análises do padrão de desenvolvimento e da crise, e o papel do endividamento na reprodução capitalista contemporânea. Procura-se, então, elaborar uma caracterização do capitalismo durante o século XX, discutindo-se o padrão de acumulação, o papel político-econômico e a autonomia do Estado e a função do endividamento. Dessa forma, ter-se-á a caracterização dos movimentos do capitalismo dentro de uma onda longa de desenvolvimento, marcada por uma fase ascendente, conhecida como "os anos dourados", e por uma fase descendente, na qual nos encontramos, marcada pelo advento da crise, estagnação e turbulência.
\end{abstract}

Palavras-chave: capitalismo, padrões de desenvolvimento, endividamento, crise.

\begin{abstract}
This article discusses the transformations of the capitalism in the $20^{\text {th }}$ century adopting as theoretical itinerary the concept of economical cycle, in which the analyses of the development pattern and crisis are enrolled, and the function of the indebtedness in the contemporary capitalist reproduction. We seek, then, to elaborate a characterization of the capitalism during the $20^{\text {th }}$ century, the political-economical function and the autonomy of the State and the role of the indebtedness. In that way, the characterization of the movements of the capitalism will be considered inside of a long wave of development, marked by an ascending phase, known as "the gold years", and for a descending phase, in which we were, marked by the coming of the crisis, stagnation and turbulence.
\end{abstract}

Key Words: capitalism, development patterns, indebtedness, crisis.

JEL: P1.

* Este artigo representa uma versão modificada de trabalho originalmente apresentado no VII Encontro Regional de Economia - Anpec Sul, Maringá (PR), 01 e 02 de julho de 2004.

** Professor do Curso de Mestrado em Economia da Universidade Federal da Bahia.

*** Professor da Escola de Administração e aluno do Curso de Mestrado em Economia da Universidade Federal da Bahia 


\section{Introdução}

Com este artigo pretende-se discutir os padrões de desenvolvimento do capitalismo no século XX, particularmente em correspondência com a fase da dialética virtuosa do capital, nos "anos dourados", e com a fase hodierna da "globalização financeira". Neste sentido, procura-se destacar o papel do endividamento como componente estrutural da reprodução e as funções do Estado capitalista neste processo. Perseguindo este objetivo, e considerando o grau de complexidade que cerca esta problemática, metodologicamente, visando a uma caracterização do capitalismo nestas duas últimas fases, aloca-se o objeto aqui destacado em uma perspectiva analítica que pressupõe uma dialética constituída por leis de movimento e reprodução que orientam o capitalismo em suas transformações. Por sua vez, esta perspectiva leva-nos à adoção dos conceitos de ciclo econômico e de crise como moldura teórica para o enquadramento da problemática acima mencionada.

Esta iniciativa, ao mesmo tempo, enseja o tratamento deste objeto em contraponto às elaborações econômicas e políticas que têm surgido nos anos recentes dando conta de um quadro novo, e potencialmente positivo, que estaria se materializando a partir da globalização, remetendo à morte dos estados nacionais. A rejeição desta última afirmação não significa, entretanto, alinhamento à tese de que nada teria mudado na relação entre o capital e Estado, o que permite efetivar a análise aqui proposta sob o pressuposto de importantes transformações das funções econômicas do Estado capitalista. ${ }^{1}$

Para esse propósito, partiremos do constructo de que as transformações recentes são resultados inerentes ao movimento reprodutivo do sistema a partir do acirramento das contradições inter e intraestatais contemporâneas. Esta contradição crescente se explica tanto pela elevação das tensões externas provocadas por modificações nas relações de coerção e controle entre a hegemon e os demais países capitalistas avançados e periféricos, com também pela ampliação dos conflitos internos em virtude de novos rumos das estratégias públicas frente à nova hegemonia das finanças. Deste modo, procura-se demonstrar que o Estado persiste com autonomia relativa e como um fator central na política, continuando a ser o lócus do poder e da disputa entre fraçōes da classe dominante, mesmo com a

\footnotetext{
1 Neste artigo será adotada a concepção marxiana de estado, qual seja, um enfoque antideterminista. Quer dizer: há uma relação dialética entre infra-estrutura (bases econômicas) e o Estado (um dos elementos da superestrutura), entrelaçados num todo, com a centralidade das relaçōes de produção. Desta forma, em Marx, a superestrutura (particularizada no Estado) não é reduzida à estrutura econômica (relações de produção).
} 
elevação do poder das empresas transnacionais e das instituições "supranacionais" no capitalismo contemporâneo. ${ }^{2}$

Para essa finalidade, além desta introdução, discute-se na segunda seção deste artigo, com base no conceito de ciclo econômico, os padrões de desenvolvimento da segunda metade do século XX, destacando as funções econômicas e políticas do Estado capitalista, o papel do endividamento no processo de acumulação, a questão da hegemonia no quadro das relações entre as nações e o novo papel das instituições supranacionais. Por fim, na terceira seção, procura-se alinhavar algumas idéias a título de conclusão.

\section{Ciclo econômico e o papel do endividamento no capitalismo contemporâneo}

Desde meados dos anos 1970, o capitalismo percorre uma trajetória distintiva relativamente àquela iniciada após o final da Segunda Guerra mundial. Neste ínterim, ocorreu um significativo recuo dos resultados fundamentais relacionados à lucratividade e à acumulação quando comparados com aqueles obtidos durante os primeiros trinta anos do pós-guerra. Experimentando um portentoso e, em certa medida, inédito período prolongado de expansão, na verdade, o capitalismo iniciara uma nova onda longa de desenvolvimento por volta de 1945 , sendo que as três décadas subseqüentes coincidem com a fase ascendente da mesma. Portanto, corresponde a uma fase em que a acumulação de capital, em média, ocorreu a taxas crescentes, e as relações capitalistas foram disseminadas intensamente por uma área mais abrangente do planeta.

Aquele foi um período de ascendência da esfera produtiva, constituindo-se em um elemento estrutural decisivo, a qual, mediante o aprofundamento da separação entre propriedade dos meios de produção e a administração das corporações, deslocou a esfera financeira para uma posição secundária. De acordo com alguns autores, em particular Duménil e Lévy (2003 e 2004), foi estabelecida uma macroestrutura que poderia ser denominada pelo termo "capitalismo gerencial" (managerial capitalism), também conhecido como

2 Apesar do antagonismo, ao longo da história, entre o Capital e o Estado, esta disputa só é realmente conflituosa quando os capitalistas são considerados de forma individual Efetivamente, o que existe é uma dialética "virtuosa e feliz", na medida em que o Estado, entre outras coisas, funcionou e funciona como instrumento da acumulação capitalista através da regulamentação e controle da circulação do dinheiro, do emprego/desemprego da força de trabalho, da divida pública e da garantia da propriedade privada. Isto quer dizer que o Estado, embora contrarie, às vezes, os interesses imediatos de capitalistas individuais, sempre atua em prol dos capitalistas enquanto coletividade. Funciona, assim, como o aparelho de regulação e coerção dos conflitos tanto entre as frações da classe dominante quanto entre as classes capitalista e proletária. 
compromisso keynesiano/gerencial. Dessa maneira, na perspectiva daqueles autores,

[...] durante os anos do compromisso keynesiano o segmento da gerência/ administração (management) obteve uma considerável autonomia relativamente aos proprietários. Este foi o caso dentro das grandes corporações, mas também dentro do aparato estatal, onde as políticas econômicas foram definidas com objetivos específicos tais como o crescimento e o pleno emprego, questões estranhas aos interesses imediatos dos proprietários. Então, o 'compromisso keynesiano' poderia ser apropriadamente denominado como um compromisso gerencial. Este foi constituído pelo capitalismo gerencial acrescido do arcabouço de políticas dos anos keynesianos, incluindo um amplo envolvimento do Estado em educação, saúde etc. (DUMÉNIL e LÉVY, 2004, p. 2).

\subsection{O desenvolvimento nos anos dourados e a estruturação do endividamento como componente da reprodução capitalista}

Entretanto, aqui se faz necessário esclarecer a adoção do dispositivo teórico-analítico escolhido. Em primeiro lugar, o conceito de ciclo econômico de curto prazo, aplicado à análise desta passagem da história do capitalismo, é completamente insuficiente para que seja efetivamente captada toda a complexidade presente naquela época. Por isso, considera-se pertinente a ampliação do conceito de ciclo econômico (business cycle), derivando-o para o conceito alternativo de onda longa (tendências históricas de prazo prolongado). Este diz respeito a um período mais extenso de desenvolvimento do capitalismo, abrangendo, em média, uma duração de cerca de 50 anos, em que se consideram, também, eventos históricos e políticos decisivos responsáveis por grandes transformações do capitalismo (KATZ, 2000). Assim procedendo, estaremos mais bem aparelhados para compreender o sucesso da introdução do padrão de desenvolvimento do pós-Segunda Guerra, principalmente na Europa.

Contudo, deve ficar claro que o modelo de desenvolvimento denominado "compromisso keynesiano" representa, antes de tudo, um conjunto de dispositivos operacionais colocados em prática visando à superação de uma crise depressiva aguda vivida pelo capitalismo e o retorno da acumulação a padrões de regularidade. Portanto, em segundo lugar, o referido deslocamento da esfera financeira deve ser analisado a partir da categoria capital financeiro, tal 
como elaborada por Hilferding (1985) e Lênin (1979). Assim posto, o capital financeiro é identificado a um fundamento estrutural que se consolida ao interior da economia capitalista na passagem do século XIX para o século XX, em particular, em alguns países da Europa, mediante a interpenetração entre a propriedade dos meios de produção e as instituições financeiras (sobretudo os bancos) por intermédio das sociedades por ações. Equivale a um processo de fusão entre banco e indústria, possibilitando a constituição de uma nova "esfera financeira" (finance), cujo objetivo é a maximização da lucratividade por intermédio de operações de lançamento e com. pra e vendas de ações, potencializando, por conseguinte, o aspecto fictício do capital envolvido neste movimento de valorização.

$O$ surgimento do capital financeiro tem entre seus principais pressupostos lógicos o movimento de centralização do capital e a expansão do monopólio, os quais, por sua vez, possibilitaram a fixação de uma nova fase do capitalismo, iniciada no final do século XIX, e se estendendo até o final da década de 30 do século seguinte. Esta onda longa, também denominada de imperialismo clássico por Mandel (1985), conheceu seu ocaso com o advento da crise depressiva aguda, abrangente e prolongada de 1929.

A Grande Depressão transformou-se em um evento complexo com manifestações muito paradoxais. Mas, antes de tudo, ela representou, na primeira metade do século XX, a conclusão de um processo que reuniu dois aspectos decisivos: por um lado, viu-se uma forte restauração do caráter tendencial das principais variáveis que expressam a vinculação entre a tecnologia e a distribuição. Por outro lado, observou-se a constituição de uma significativa fraqueza institucional, sobretudo, no que tange ao sistema bancário e aos mecanismos de controle social da instabilidade. Neste contexto, pressuposto o movimento cíclico inerente à onda longa, e a inflexão de uma fase ascendente para uma fase descendente, este período pode ser também caracterizado como aquele em que ocorre, ao longo do século passado, uma primeira hegemonia financeira (DUMENIL \& LÉVY, 1999, p. 27; 2004). Portanto, a finalização desta crise de superprodução exigiu uma profilaxia drástica e amplamente destrutiva de mercadorias, capitais e força de trabalho de forma a permitir o estabelecimento de uma nova plataforma de relançamento da acumulação.

Concluída a onda longa precedente, a retomada da acumulação no pós-Grande Depressão coincide com o ponto de partida de uma nova onda longa de desenvolvimento do capitalismo, que prossegue até os dias atuais, entretanto, agora, já em sua etapa recessiva. A primeira fase (1933/45-1975) desta onda longa, quer dizer, seu seg- 
mento expansionista, se inicia, portanto, com o New Deal. Aquele programa de recuperação da economia americana, como se sabe, inaugura uma nova macroestrutura econômica do capitalismo, cuja marca decisiva seria a reformulação da presença estatal na economia, não apenas em termos normativos, mas, também, como esfera (ramo) da produção. Esta acentuada inflexão relacionada às atribuições econômicas designadas ao Estado capitalista baseou-se em um inquestionável aparato de regulação com o propósito principal de enquadramento do capital financeiro e seu direcionamento para o financiamento da produção.

Em linhas gerais, a estratégia de recuperação econômica assentada no princípio da economia da demanda efetiva (o New Deal), foi consubstanciada a partir das seguintes diretrizes: (i) redução da influência dos condicionantes externos sobre as políticas macroeconômicas domésticas; (ii) repressão financeira, qual seja, a implantação de mecanismos de administração por parte das autoridades monetárias sobre a moeda de crédito, e o capital a juros, através do processo de monetarização da dívida pública; (iii) mediação estatal entre a gerência empresarial e os trabalhadores, através de suas representações sindicais, visando à articulação entre o aumento dos salariais reais, os ganhos de produtividade e o comportamento dos preços; (iv) incorporação dos gastos públicos, dos investimentos diretos, e das transferências de seguridade social, como componentes basilares da demanda (BELUZZO, 1999; GUTTMANN, 1998).

Sem dúvida, ficava claro que o capitalismo resolvera adotar um modelo de desenvolvimento de inquestionável inspiração keynesiana, portanto, privilegiando o princípio da demanda efetiva como norma teórica. Uma vez que, no período anterior ao crack da bolsa de Nova York, predominara uma concepção muito mais apoiada no principio do laissez-faire, base doutrinária que garantia privilégios para o capital financeiro, a enorme montanha de capital fictício que se constituíra, e o elevado grau de instabilidade inerente à mesma deveriam ser substituídos por mecanismos que assegurassem a redução ao máximo da incerteza intrínseca do sistema. Entre estes mecanismos destaque-se a estrutura reguladora implementada por Roosevelt em relação à moeda e ao sistema de crédito, ou seja, uma nova ordem monetária em que as autoridades monetárias do Estado (Banco Centrais) podiam interferir na oferta de moeda tanto de forma direta, alterando a quantidade de moeda em circulação, quanto de forma indireta, por meio da regulação das atividades de criação monetária dos bancos comerciais. Tornar-se-ia possível, assim, a criação de uma oferta elástica de moeda a juros baixos através do au- 
mento das despesas financiadas por endividamento. Esse processo deu origem a uma monetização das dívidas, e permitiu financiar, simultaneamente, os déficits orçamentários crônicos do Estado previdenciário, os investimentos necessários à difusão de tecnologias da produção fordista, e as normas de consumo de massa de bens mais caros, tais como, automóveis e casas (GUTTMANN, 1998).

O excesso de liberdade para os movimentos dos capitais daria lugar a uma condução econômica de perfil anticíclico. Desta forma, o papel da demanda agregada passava a ser decisivo, o que implicou a elevação para o primeiro plano de dois elementos desta macroestrutura, a saber, os gastos em consumo privado e as despe. sas público-estatais.

No que diz respeito à função do consumo neste modelo, tornou-se necessário o estabelecimento de uma estrutura institucional de reforçamento dos rendimentos do trabalho e de elevação do emprego a patamares equivalentes ao conceito de pleno-emprego keynesiano. Por essa razão, sob determinados aspectos, pode ser dito que a integração entre o Estado e a gerência empresarial resultou em um "Pacto Social" que incorporou os trabalhadores através de suas representações sindicais e dos partidos reformistas de origem operária. Simultaneamente, ao tempo em que se observou a expansão de empregos e salários, também foi implantado um aparato público de proteção social (Welfare State) cuja resultante se revestiu de considerável elevação dos diretos sociais das amplas massas trabalhadoras. Fica assim muito claro que o dispositivo regulatório aplicado ao mundo do trabalho, em sua relação com o capital, constituiu-se enquanto necessidade para a retomada dos niveis de lucratividade e das taxas de acumulação que o capitalismo vira desaparecer com a eclosão da crise de superprodução ao final da onda longa precedente.

Se os EUA aparecem como o espaço capitalista pioneiro de desenvolvimento deste modelo, certamente porque aquele país tornara-se o epicentro da grande depressão, também a Europa e o Japão, em função de um evento histórico de grande envergadura, conheceriam a aplicação do mesmo, sobretudo quando da adoção das medidas necessárias à reconstrução depois do fim da Segunda Guerra Mundial. Em particular, deve ser destacada a afinidade do Plano Marshall, aplicado à reconstrução dos países capitalistas da Europa Ocidental, à natureza do New Deal. Por conseguinte, essa orientação econômica, que visava à recolocação da economia capitalista nos trilhos de uma nova fase expansionista, é introduzida, principalmente, naquele núcleo de países que passaria a ser considerado como a ponta avançada do sistema no plano mundial. 
A fase de expansão econômica do pós-Segunda Guerra, que prosseguiu até meados dos anos 1970, esteve vinculada à capacidade do núcleo de países capitalistas avançados de realizar e sustentar altas taxas de lucro, produzindo a geração de excedentes econômicos relativamente elevados a partir do uso de capital fixo/estoque de capital (instalações e equipamentos). ${ }^{3}$ As expressivas taxas de lucro alcançadas pelas economias avançadas propiciaram a manutenção de elevados índices de investimentos, acelerando a produtividade, associados ao rápido crescimento dos salários reais sem ameaçar os lucros (BRENNER, 2003). Nesse período, a maioria das economias capitalistas avançadas, e algumas subdesenvolvidas, vivenciaram um longo boom econômico, alcançando índices historicamente inéditos de crescimento da produçăo, da produtividade e dos salários, ao tempo em que experimentaram pequenos índices de desemprego e processos recessivos mínimos.

Desta forma, a expansão econômica dos anos dourados foi materializada a partir da articulação entre crescimento das taxas de lucro e dos salários reais - economia da demanda efetiva. No entanto, ainda no contexto a teoria da onda longa, se faz necessário dar destaque aos eventos histórico-políticos que contribuíram para o sucesso deste modelo em termos sistêmicos. Assim, o evento da Segunda Guerra e seus desdobramentos, em particular a constituição e afirmação do chamado Bloco Socialista, capitaneado pela URSS, conformou a divisão do mundo em dois pólos, duas grandes áreas de influência, mediante os acordos de "coexistência pacífica" firmados no ocaso daquele conflito bélico. No pólo capitalista, os Estados Unidos buscaram assegurar o êxito econômico para seus aliados e concorrentes como forma de consolidar a ordem capitalista - um mundo seguro para a livre empresa - e combater o "perigo comunista". Nesse cenário, o estado imperialista americano, enquanto centro hegemônico já consolidado, arquitetou uma cooperação antagônica entre os principais países capitalistas, ou seja, uma cooperação entre Estados capitalistas concorrentes, alçando o crescimento econômico a uma questão de segurança nacional (THALHEIMER apud MEYER, 2000).

Mesmo assim, o processo de expansão mundial não ocorreu de forma homogênea dentro do núcleo dos países avançados. Tampouco seria possível constatar-se uma simultaneidade de ritmos entre os mesmos. Na verdade, os EUA, face suas condições materiais e econômicas privilegiadas ao final da Segunda Guerra Mundial,

3 Entre 1950 e 1973, a taxa de lucro líquido, em média anual, foi de $24,35 \%$ nos EUA, $23,1 \%$ na Alemanha e 40,4\% no Japão (BRENNER, 2003). 
saltaram à frente, experimentando uma trajetória de crescimento temporalmente desigual relativamente à Europa e ao Japão. Mais tarde, quando estes últimos, superados os obstáculos inerentes à reconstrução, atravessam seus auges expansionistas, a economia doméstica americana já vivenciava um processo de declínio relativo. Todavia, por conta desta dinâmica mundial diacrônica, os EUA garantiram a continuidade da vitalidade das forças dominantes internas, pois o desenvolvimento tardio da Europa e do Japão representou, por um lado, oportunidades de expansão externas para as empresas multinacionais e os bancos americanos, abrindo novos canais de lucratividade para os seus investimentos diretos, e, por outro, asseguraram o crescimento das exportações dos produtores internos que perseguiam uma demanda estrangeira de crescimento acelerado (BRENNER, 2003).

Deste modo, o êxito econômico americano estava atrelado ao sucesso de seus parceiros capitalistas. Tal vinculação propiciou um maior grau de cooperação e coordenação internacional - Plano Marshall e sistema financeiro internacional "regulado" -, marcadas por forte apoio político-econômico dos norte-americanos a seus aliados e concorrentes, ainda que sob hegemonia dos Estados Unidos. Nesse período, a hegemonia americana foi exercida através de um comportamento dual: coercitivo e persuasivo, com o aspecto persuasivo ocupando maior destaque na política internacional norte-americana (MEYER, 2000).

Detalhemos, por conseguinte, como os fenômenos econômicos se entrelaçam com as iniciativas políticas e os eventos históricos para produzirem um quadro de profundas transformaçōes. Como se sabe, a depressáo econômica, que se abateu sobre a Europa, propagada a partir dos EUA, quando este já naquela altura se transformara no coração do sistema capitalista mundial, evoluiu para um cenário de destruição aberta com o advento da II Guerra. O fim do conflito bélico encontrou a Europa em uma situação de correlação de forças completamente modificada, na qual se destacava, combinadamente, a incorporação de vários países europeus até então capitalistas à orbita da União Soviética, e o surgimento de situações revolucionárias objetivas favoráveis às posições dos trabalhadores naqueles países da Europa ocidental que permaneceriam sob o comando capitalista, tais como, a saber, a França e a Grã-Bretanha.

Destarte, a aplicação dos códigos regulatórios de favorecimento ao trabalho coincide com um elenco de reivindicações trabalhistas por melhorias de condições de vida e de direitos. $O$ mesmo pode ser dito a respeito da nova concepção de intervenção estatal na eco- 
nomia, já que a profunda destruição econômica provocada pela guerra, de amplas conseqüências deletérias, não poderia ser revertida rapidamente apenas com base nos mecanismos espontâneos do mercado e da livre-iniciativa. Temos aqui, portanto, a intervenção de eventos do plano político que colaboraram para a implementação do chamado compromisso keynesiano, de forma até mais abrangente, na Europa ocidental, ou na Europa que permaneceria capitalista depois dos acordos de coexistência pacifica firmados entre EUA, Inglaterra e URSS ao final da Segunda Guerra.

Esta arquitetura de governança e coordenação seria ainda expandida para uma dimensão internacional mais ampla. O capitalismo colocou em prática um mecanismo regulatório direcionado para o controle das relações entre países, abarcando, dessa maneira, os fluxos financeiros, de capitais e de mercadorias. A partir da substituição do padrão-ouro pelo padrão-dólar, refletindo a ocupação pelos EUA do lugar de potência hegemônica no lugar da Inglaterra, os acordos de Breton Woods resultaram na construção de uma estrutura institucional baseada em organismos como o FMI, o Banco Mundial e o GATT. A principal preocupação vinculava-se à necessidade de evitar mudanças bruscas e imprevisíveis, amenizando a autonomia dos fluxos financeiros especulativos e potencialmente portadores de elementos desestabilizadores. Depois de 1944, quando os acordos de Breton Woods foram firmados, prevaleceu até 1971 um controle relativo que acabou por privilegiar os fluxos de mercadorias e de investimentos diretos mediante um sistema de taxas de câmbio fixas fortemente administradas.

Tendo em vista o propósito principal deste trabalho, vejamos agora de forma mais detalhada a nova função econômica estatal nessa etapa da história do capitalismo. Parte-se, então, da afirmação que define o Estado como uma componente estrutural indispensável ao padrão de acumulação colocado em prática naquele período. Este redimensionamento tem como uma de suas facetas o funcionamento do Estado como uma esfera particular ao interior da divisão social do trabalho da economia. Todavia, não corresponde integralmente, e nem poderia, ao conceito de esfera produtiva tal qual aquelas inerentes à categoria capital industrial como teorizado por Marx (1986) em sua interpretação da reprodução capitalista. No padrão de desenvolvimento dos anos dourados, o Estado cumpre uma atuação tipicamente keynesiana, o que significa dizer que passa a se responsabilizar direta e indiretamente pela efetivação de uma determinada taxa de investimento. Neste sentido, o investimento, como componente da demanda estatal, independe do processo conven- 
cional de formação de expectativas, o qual confere a esta variável, sob condições inerentes à lógica do processo de tomada de decisão do empresário privado, um elevado grau de incerteza, constituindo-se, por conseguinte, em fonte de instabilidade sistêmica.

Além disso, o Estado passa a ser uma fonte de financiamento fundamental ao capital produtivo. Tendo em vista a atrofia da esfera financeira e seu descolamento relativamente à esfera produtiva, tal como ocorrera no período anterior à Grande Depressão, as amplas reformas introduzidas pelo New Deal, e propagadas para a Europa e Japão, conduziram a uma modificação drástica da estrutura de financiamento da economia. Esta passou a refletir uma ampliação da atuação estatal neste campo. Bancos, agências de financiamento e organismos de fomento de caráter público/estatal foram criados. O próprio segmento financeiro privado foi objeto de um amplo saneamento e ficou sujeito a uma legislação voltada para o estímulo das atividades produtivas. Este dispositivo, por essa razão, se constitui na outra faceta relacionada à importância adquirida pelo endividamento público, ampliando o significado anticíclico do déficit orçamentário.

Vê-se assim como são criadas as condições para a consolidação da dívida pública como elemento perene da estrutura da reprodução capitalista. Evidentemente, o Estado esteve sempre participando desde o início do capitalismo dessa reprodução. Entretanto, fazia-o de forma subsidiária e errática, inclusive, a este propósito, não presente teoricamente no escopo da economia política burguesa predominante até então. A partir do New Deal, os gastos governamentais e sua contrapartida, o déficit orçamentário, tornaram-se elementos permanentes e decisivos da trajetória expansionista registrada até meados da década de 1970. E, em termos teóricos, o keynesianismo, e suas vertentes "bastardas", se transforma no mainstream da ciência econômica.

Neste contexto, o gasto público adquire um significado virtuoso inquestionável na dinâmica capitalista. Sem sombra de dúvida, em meio à fase de prosperidade experimentada pelos capitalismos centrais, a dívida pública tem uma componente produtiva de grande relevância. Acoplada aos elementos favoráveis à ascensão da acumulação de capital, tais como a inovação tecnológica e organizacional, o novo padrão de consumo de massas e a ampliação dos mercados mediante a introdução das relações capitalistas em novos espaços geográficos do planeta, a dívida pública cumpriu seu papel a contento sem se transformar em fonte de instabilidade. Portanto, a transferência de parte do excedente social para o Estado - 
e sua redistribuição sistêmica integradora de um mecanismo reprodutivo favorável aos capitais privados na esfera não financeira - foi tolerada sem maiores questionamentos até que este padrão de desenvolvimento começasse a fazer água.

\subsection{Crise, estagnação e turbulência pós anos 1970: a nova função do endividamento}

A fase expansiva de cerca de três décadas esgotou-se finalmente em meados dos anos 1970. Desde então, a economia capitalista passou a conviver com uma significativa inflexão da taxa geral de lucro e dos níveis de acumulação gerados por uma grave crise de excedentes de produção e de capacidade. Em paralelo, como conseqüências típicas dos processos recessivos, a redução das taxas de investimento e crescimento foi acompanhada de resultados sociais amplamente negativos. Entre outros, destaca-se a elevação do desemprego em caráter crônico, principalmente, nos países avançados da Europa ocidental e nos EUA (BRENNER, 1998). ${ }^{4}$ Articulados ao dispositivo econômico da crise despontam três movimentos histórico-políticos relevantes para ò entendimento dessa nova dinâmica capitalista, quais sejam: a contestação da hegemonia americana, uma posterior retomada desta hegemonia, e, por fim, a queda do bloco socialista.

Como acontece quando as taxas de lucro recuam, primeiramente, no contexto do ciclo econômico curto, mecanismos são acionados procurando a reversão das mesmas. Porém, o período inaugurado nos anos 1970 logo revelaria a presença dos elementos característicos das fases descendentes das ondas longas. Tornara-se claro que, dentro da onda inaugurada com o New Deal, acontecera uma reversão da sua fase expansionista para a sua fase de contração. Diante de um quadro reticente no que tange à fixação de novas taxas de expansão da economia, importantes e contraditórias transformações estruturais de grande envergadura foram introduzidas. Isto quer dizer que os cânones keynesianos foram quebrados para promover uma nova rota de acumulação assentada na abertura de espaços para a acumulação rentista, tanto quanto para a viabilização do incremento da extração da mais-valia, seja de forma relativa, via reestruturação produtiva, seja de forma absoluta, por meio da flexibilização das relaçōes de trabalho.

4 Entre 1970-79 a taxa média anual de desemprego nos EUA foi de 6,2\%, enquanto no período 1980-89 a mesma alcançou 7,3\%. Ao mesmo tempo, na Europa, nos mesmos períodos, a taxa média anual de desemprego atingiu 3,7\% e 8,8\% respectivamente (BRENNER, 2003). 
Deste modo, o capitalismo chega a um momento em que, ao tempo em que passa a atuar em todos os espaços do Planeta e coloca em prática um novo paradigma tecnológico, também promove uma série de mudanças relacionadas ao papel do Estado na economia, à função do trabalho na reprodução capitalista e à intensificação do conflito político-econômico internacional entre os países capitalistas avançados. Chega-se a um padrão popularmente conhecido como globalização, ou, em termos conceituais mais formais, como a dinâmica neoliberal (DUMÈNIL e LÉVY, 2003).

Em um cenário marcado pela crise de excedente e pelo avanço do poder econômico do Japão e da Alemanha, os Estados Unidos vêem sua hegemonia contestada dentro dos marcos do sistema capitalista. Este questionamento ocorreu tanto na dimensão econômica - ameaça da posição do dólar como moeda de reserva internacional pelo marco e iene, entre 1977 e 1978 - quanto na dimensão geopolítica - derrota no Vietnã e crise dos mísseis em Cuba, além do fortalecimento militar da Uniāo Soviética e da China. Vejamos, de forma estilizada, alguns dos fatos históricos políticos e socioeconômicos, ocorridos entre meados das décadas de $1960 \mathrm{e}$ de 1970, que influenciaram o processo de contestação da hegenom e, por outro lado, possibilitaram o início da retomada norte-americana, abrindo espaço para a globalização financeira e, por conseguinte, para a emersão do rentismo, que fora mantido sobre controle relativo durante os anos dourados.

- As taxas de crescimento, da produtividade e dos lucros nas economias capitalistas avançadas são desaceleradas em função do excesso de capacidade e de produção;

- Os fabricantes localizados em blocos econômicos de desenvolvimento mais tardio, notadamente japoneses e alemães, passam a confrontar os produtos americanos em preços no mercado mundial;

- A economia americana enfrenta déficits astronômicos do balanço de pagamentos, em virtude dos investimentos externos crescentes e dos gastos associados à Guerra do Vietnã, que elevam a quantidade de dólares no exterior, provocando uma pressão de desvalorização sobre a moeda americana, levando à crise do sistema monetário mundial;

- Por conseqüência, em agosto de 1971 a administração Nixon, de forma unilateral, decreta o fim da conversibilidade do dólar, liberando o governo americano da exigência de reduzir seus déficits externos. Em face disso, tornou-se inevitável a ruína do sistema monetário de Bretton Woods, de relativa rigidez das taxas de câmbio e de taxas de juros fixadas em patamares reduzidos;

- Ocorre um colapso temporário da demanda mundial durante a crise do petróleo de 1974-75; 
- As economias avançadas recorrem uma vez mais, agora excepcionalmente, aos déficits keynesianos, em larga escala, que geram intenso crescimento da dívida pública, possibilitando a superação temporária da crise do petróleo através do subsidio à demanda. Contudo, o remédio keynesiano não limpou o caminho para novas expansões: na verdade, perpetuou o excesso de capacidade e produção combinada com elevação de preços, gerando estagflação;

- Entre 1977 e 1978, "os Estados Unidos batiam de frente com o limite de tirar vantagem do papel do dólar como moeda-chave ao incorrerem em sempre maiores déficits federais e de conta corrente e desvalorização a fim de conquistarem uma crescente expansão econômica e competitividade do setor manufatureiro" (BRENNER, 2003, p.78);

- O governo norte-americano buscou aumentar a mobilidade de capital para financiar os déficits do balanço de pagamentos através do crescimento da emissão da dívida pública. Isto facilitou seus planos para a retomada do crescimento da economia e, ao mesmo tempo, fortaleceu os interesses financeiros domésticos dos principais bancos do país.

Com sua hegemonia questionada, seja dentro do sistema-mundo ocidental, ou na dimensão imperialista mundial, o governo ame* ricano decidiu implementar uma "virada" em suas estratégias internas e externas. Economicamente, a "diplomacia do dólar forte" encaminhada por Paul Volcker, engendrada no ano de 1979, tinha como objetivo estratégico enquadrar os países sócios e os principais competidores econômicos do mundo capitalista. Como a principal ferramenta utilizada naquela política foi uma expressiva elevação das taxas de juros, ocorreu uma reversão da direção dos fluxos de capitais da Europa, Japão e, principalmente dos países subdesenvolvidos, para os Estados Unidos, já que outrora este era o principal exportador de capitais. Este processo permitiu o equilíbrio da balança de pagamentos americana, uma vez que o fluxo de capitais oriundo do exterior mostrou-se suficiente para cobrir o crescente déficit público daquele país.

O novo cenário, caracterizado por uma combinação de queda de lucro com superprodução e estratégias de retomada da hegemonia americana, acabou por orientar o sistema em direção a formas alternativas de recuperação da lucratividade, atreladas a transformações políticas no âmbito nacional e internacional. Esta situação, porém, acabou por abrir espaço para o reflorescimento daquela fração das classes dominantes do sistema capitalista que fora mantida sob controle relativo durante o padrão de acumulação dos anos dourados. Isto porque, o novo ambiente estabelecido para o soerguimento da lucratividade, muito embora se apresentasse potencialmente eficiente de per se, do ponto de vista prático represen- 
tava inexoravelmente uma reativação das condições favoráveis à realização do lucro predominantemente em sua forma financeira, acarretando com isso a introdução de enormes dificuldades para a transformação do mesmo em acumulação mediante a promoção do capital produtivo.

Assim, mais uma vez durante o século XX, novamente em consonância com a fase descendente de uma onda longa, o capitalismo se depara com pesadelo da hegemonia das finanças. O retorno das finanças ao primeiro plano é caracterizado por Duménil e Lévy como uma segunda hegemonia financeira ou, ainda, como a globalização neoliberal:

O neoliberalismo é uma ordem social que emergiu da destruição do compromisso social anterior, com a restauração do poder das finanças. Apesar da violência desta nova ordem social, o neoliberalismo é compatível com a 'democracia' (...). Assim, o neoliberalismo é também baseado em compromissos. Dois aspectos devem ser enfatizados. Primeiro, o retomo das finanças teve como suposto uma estrita aliança com os altos executivos (top management). Esta foi efetivada mediante elevadíssimas remunerações, tais como 'salários' e opções em ações. Segundo, as frações mais elevadas dos assalariados e das classes médias autônomas se associaram a um novo curso da economia favorável aos proprietários do capital, já que se tornaram proprietários de aplicações financeiras diretamente ou junto a fundos. Com taxas de juros elevadas e mercados acionários em expansão meteórica, estas classes, investindo principalmente em seus fundos de pensão, passaram a ter a impressão [...] de compartilharem as condições de proprietários capitalistas. Neste complexo padrão de relações de classes, as finanças dominam os outros componentes do compromisso neoliberal. Como descrição das relações internacionais, o termo 'hegemonia' é adequado para designar a posição das finanças nesta configuração de poder: o domínio sobre um grande grupo, o que também significa o domínio sobre o resto da sociedade (DUMÉNIL e LÉVY, 2004).

Nesta altura deve ser reafirmada a tese aqui apresentada a respeito do conceito de hegemonia financeira. Esta se refere ao poder e autoridade exercidos, sobre a economia, pelos proprietários mais ricos do capital e também pelas instituições financeiras. Nesta estrutura, aos estratos mais altos da gerência e às camadas mais elevadas da administração das empresas são impostos os objetivos das finanças (DUMÉNIL e LÉVY, 2004).

Porém, convém lembrar que, em condições ordinárias, o mecanismo reprodutivo regular do capitalismo logicamente conta com uma superestrutura financeira completa orientada para o financia- 
mento do capital produtivo. Atuando como componente da divisão do trabalho entre diferentes modalidades funcionais do capital, ela é uma representação do capital portador de juros, o qual, por sua vez, se origina do capital industrial. Apesar da existência desses vínculos orgânicos, a superestrutura financeira tem uma tendência à aquisição de uma autonomia relativa mediante a instalação de um aparato creditício-financeiro constituído pioneiramente como aporte à esfera da economia na qual ocorre a geração da mais-valia (MARX, 1986).

Por outro lado, empiricamente, nesta fase descendente do capitalismo, a superestrutura financeira envereda por uma trajetória de descolamento atrofiado relativamente à esfera produtiva. Quando do aparecimento dos primeiros sinais de esgotamento da fase expansiva correspondente ao período 1933/45-1975, iniciou-se um processo inovativo no campo das finanças, possibilitando a abertura de novos espaços para o capital fictício. A origem desta atrofia deve ser localizada na obstrução encontrada pelo capital para retornar aos patamares pretéritos da taxa geral de lucro obtidos com a produção de mercadorias strictu sensu. Esta dificuldade levou o capitalismo a voltar-se preferencialmente para alternativas de lucro centradas em fundamentos financeiros. Dessa forma, o capital-dinheiro passa a circular com um grau de autonomia superior relativamente ao predomínio da macroestrutura keynesiana do pós-guerra, indicando, portanto, o enfraquecimento dos canais até então constituídos para o financiamento da esfera produtiva.

Mesmo assim, concomitantemente, importantes modificações produtivas e organizacionais foram também lançadas tendo em vista o enfrentamento da taxa de lucro cadente. Estas, em grande medida, estão vinculadas à força de trabalho, tanto em termos da remuneração quanto da produtividade. Por essa razão, ocorre a alavancagem de uma onda de inovações tecnológicas, a qual, entretanto, não se desdobrou em retomada sustentada da acumulação. A chamada "terceira revolução tecnológica", associada a outros fatores, que analisaremos mais à frente, além da financeirização, acabou por estabelecer uma estrutura marcada por turbulência e estagnação.

No contexto desta nova hegemonia financeira, materializa-se uma situação de desaceleração ou estagnação do nível de atividade da economia mundial, inclusive nos países capitalistas avançados, tais como, Japão e União Européia, que enfrentaram taxas de crescimento reduzidas durante as décadas de 1980 e 1990. A exceção fica por conta dos EUA, particularmente na segunda metade dos anos 1990, em virtude dos seus ganhos de corretagem sobre o capital financeiro nacional e internacional e das políticas keynesianas 
parciais configuradas a partir de gastos bélicos. Esta estagnação econômica mundial vincula-se à queda dos investimentos produtivos privados e à redução dos gastos públicos e de consumo. As origens das assimetrias entre esses países avançados estão assentadas no perfil macroeconômico (componentes da demanda efetiva) e no caráter da reprodução e da acumulação financeiras.

A reestruturação produtiva, em associação com a acumulação financeira, produziu estagnação econômica na maioria dos países avançados e periféricos, o que acabou por desorganizar o mercado de trabalho de diversos países. Os índices de desemprego, nas décadas de 1980 e 1990, alcançaram patamares elevadíssimos, inclusive, nos países capitalistas avançados, em franco contraste com a situação de quase pleno-emprego observada nos anos dourados.

As amplas medidas de desregulamentação que os países centrais implementaram, sobretudo os EUA e a Inglaterra, foram também impostas ao conjunto dos demais países como conseqüência das políticas americanas utilizadas para a efetivação da retomada de sua hegemonia político-econômica. Em primeiro lugar, a desregulamentação pode ser vista pela ótica do desmonte da estrutura que dava sustentação ao compromisso keynesiano. Em segundo lugar, seu perfil está associado ao aprofundamento da integração dos Estados nacionais ao mercado mundial, facilitando os movimentos do capital financeiro, e a desvalorização da força de trabalho mediante a ruptura de códigos de proteção ao trabalho assalariado formal.

Efetivamente, o fenômeno da financeirização tornou-se possível devido à forte redução das restrições enfrentadas pelos capitais individuais quando, em virtude da contração da taxa geral de lucro, buscavam um diferencial positivo de rentabilidade de seus investimentos financeiros relativamente aos investimentos produtivos (SALAMA, 2000). O capital em sua forma dinheiro, dirigido para a geração de juros, passa a ter sua rentabilidade potencializada por um conjunto de ativos, agentes e instituições creditício-financeiras, representado um universo multifacetado inédito vis-à-vis os tradicionais agentes da esfera financeira. Há agora uma institucionalidade composta por corporações, governos e agentes negociadores de papéis das mais diferentes modalidades, os quais remuneram os investidores com base em riqueza previamente inexistente, acentuando, dessa maneira, o caráter especulativo em seu interior (McNALLY, 1999).

Nesta nova fase, o endividamento, a variável virtuosa no período prolongado de crescimento desta onda longa, continua ocupan- 
do um lugar decisivo, porém, agora, com um conteúdo bastante modificado. O mecanismo do endividamento desta vez está ligado à garantia da alta lucratividade para as finanças, mas, ao mesmo tempo, representa um padrão contraditório que reúne revolução tecnológica, aumento da produtividade, baixo crescimento econômico e elevação da instabilidade. Dentro deste marco, o endividamento se transforma num problema crônico, perpassando os setores público e privado e consolidando, nesta fase do capitalismo, um ambiente de crise recorrente (KLIMAN, 2000).

A título de ilustração, constata-se que, na década de 1980, o endividamento público cresce expressivamente nos principais países capitalistas. Os dados mostram que, no Japão a dívida cresce para $72,1 \%$ do PIB, na União Européia alcança $63,0 \%$, enquanto, principalmente, nos EUA a dívida atinge $68,7 \%$. Neste contexto, a dívida pública constitui-se inequivodamente em um elemento fulcral do processo de securitização. E, em virtude da grande liquidez de que são dotados os papéis do governo dos Estados Unidos, demandados tanto por agentes privados estadunidenses, como também por agentes de outros países, cresce exageradamente a participação dos títulos americanos na formação da riqueza financeira, (BELUZZO, 1999).

Alguns aspectos relevantes foram consolidados como elementos intrínsecos dessa nova arquitetura financeira. Em primeiro lugar, no que tange ao comportamento dos proprietários do capital e dos consumidores de alta renda, aparece o fenômeno denominado por Chesnais de "efeito mercado acionário". Este se desdobra em dois componentes, a saber, um "efeito-renda", que financia o consumo a partir de dividendos e juros, e um "efeito posse de patrimônio", que viabiliza a realização de despesas apoiadas em antecipações de ganhos financeiros futuros (CHESNAIS, 2001).

A instituição da liquidez absoluta como objetivo exclusivo dos investidores é o comportamento distintivo relativamente ao mercado financeiro tradicional. Neste, havia o interesse primordial de recebimento de dividendos, enquanto atualmente se busca a liquidez a mais ampla possível. Para isso não necessários mecanismos que viabilizem a apropriação de excedentes bursáteis através de escolhas alternativas amplas mediante o encaminhamento das aplicações instantaneamente para os mais diferentes espaços intra-nacionais e internacionais. Assim, as finanças exigem cada vez mais mercados financeiros amplos, onde as transações ocorram livremente em busca de revalorização de títulos e recomposição de portfólios. É, por conseguinte, uma estrutura ideal, já que correspondem a 
mercados que combinam originalmente o favorecimento da especulação e a facilitação das "retiradas" estratégicas (CHESNAIS, 2001).

Em segundo lugar, por outro lado, a função do endividamento, para efeito de retorno à lucratividade do capital financeiro, se estende para o plano das relações entre as nações. Evidentemente, historicamente, estas relações são caracterizadas por uma desigualdade explicita e por uma determinada hierarquia sempre em mutação. Pode ser afirmado, portanto, que a nova arquitetura das finanças internacionais, correspondendo a esta lógica, estrutura uma nova face da chamada "exportação de capitais". O receituário neoliberal, em seu conteúdo desregulatório, viabiliza a implantação de um escoadouro dos excedentes de capitais cujos proprietários optam por não transformá-los em investimentos produtivos. Parcela significativa da chamada liquidez financeira do mercado internacional flui sem obstáculos entre os países centrais e os países atrasados, sobretudo, na forma de aplicações especulativas.

Particularmente, a partir dos anos 1970, os países atrasados adotaram o endividamento como via principal de desenvolvimento, estratégia que se transformou em um dos elementos mais significativos da estrutura contemporânea da reprodução capitalista. Mas, na verdade, no novo padrão de acumulação, aquele que Chesnais (1996) denomina de "regime de acumulação predominantemente financeiro", a dívida dos países dependentes substituiu as políticas de desenvolvimento orientadas pelo setor público, as quais, em que pese a manutenção do subdesenvolvimento nestes países, visavam à dinamização da atividade produtiva e a expansão do mercado interno.

A estrutura do endividamento convive lado a lado com crises recorrentes no capitalismo contemporâneo, conformando um círculo vicioso, há cerca de três décadas. Impossibilitado de ingressar em uma nova onda longa de crescimento sustentado, este regime experimenta continuamente turbulência e estagnação. Isto é ainda mais relevante quando se percebe - diante da fragilidade dos países atrasados e das oscilações dos países centrais - a ausência de qualquer indicação que aponte para uma mudança de rumos. Atualmente, a impossibilidade de um colapso sistêmico depende de um processo precário de coordenação monetária e política ainda em vigor, o qual, nos últimos anos, conseguiu amenizar os efeitos multiplicadores deletérios de bancarrotas em países periféricos e manter o frágil controle da situação após o estouro de bolhas especulativas nas bolsas de valores (KATZ, 2002). 
A questão do endividamento possui uma complexidade mais ampla como componente estrutural da crise capitalista. Assim, ainda no plano das relações entre Estados nacionais, a continuidade do pagamento do serviço da dívida e, ao mesmo tempo, a remuneração generosa do capital estrangeiro especulativo, empurraram os países dependentes para uma posição funcional no escopo da reprodução da crise. Por conta dessa funcionalidade, estão obrigados a praticarem políticas de ajuste macroeconômico de forte contenção inflacionária por intermédio de medidas restritivas do nível de atividade interna. Em paralelo, o crescimento do endividamento interno, mediante a oferta de títulos públicos a juros generosos ao capital financeiro, se transformou em uma componente cotidiana deste processo.

\subsection{As instituições "supracionais" na nova funcionalidade do endividamento}

Viu-se até aqui que o endividamento desempenha uma função indispensável na reprodução capitalista. Porém, agora, essa funcionalidade assegura a reprodução num contexto de crise. Mesmo assim, ele não deixa de ocupar um papel estrutural determinante. Por essa razão, mais do que nunca, as instituições criadas pelos acordos de Breton Woods confirmam sua importância para o capital, embora a orientação das mesmas passe a ter propósitos invertidos. O FMI, principalmente, impôs um conjunto de reformas que inclui a desregulamentação e a flexibilização sobre os países periféricos. A coordenação visa agora atender a novas perspectivas de remuneração do capital dinheiro, amplamente especulativo. As taxas de juros internas passaram a ter uma importância fundamental. Juros altos e taxas de câmbio flutuantes dão suporte ao arsenal especulativo representado pelo surgimento de um número muito elevado de inovações ocorridas no setor financeiro, entre elas, a criação dos derivativos, o mercado secundário para a divida dos países atrasados, a importância da especulação em bolsa de valores e um impressionante mercado de especulação com moedas nacionais.

Para asseverar a rentabilidade máxima do capital em sua forma financeira, em sua fuga à tendência baixista da crise, tornou-se necessário a introdução de mecanismos de potencialização da sua mobilidade dentro de determinados parâmetros inerentes à relação espaço-tempo, enquanto em sua forma produtiva elevou-se desmesuradamente a coerção sobre o trabalho. Neste sentido, as amplas medidas de desregulamentação financeira e os ajustes estruturais que os estados centrais, sobretudo os EUA, passaram a impor, via 
Banco mundial, Fundo Monetário Internacional (FMI) e Organização Mundial do Comércio (OMC), aos estados nacionais em geral, deram formatação a um novo quadro político-econômico que se materializou na aplicação do chamado receituário neoliberal.

Não surpreende, portanto, que, com a crise, estas instituições econômicas "supranacionais", tenham se fortalecido, uma vez que elas continuam a desempenhar, só que agora de forma amplificada, funções relevantes para o ajuste integrativo dos espaços mundiais, à luz das novas condições de produção e reprodução do capital. Fica patente a preocupação embutida nos principais movimentos efetuados por estas instituições, estreitamente identificadas com os seguintes eixos dominantes: i) a universalização do capitalismo enquanto eixo da esfera econômica; ii) a democracia liberal no campo político; iii) a generalização dos valores culturais coerentes com as perspectivas liberais. Este ideário torna-se uma quase obrigação a ser cumprida pelos países que disputam empréstimos ou ajuda financeira, principalmente, nos momentos em que encontram dificuldades de captação de recursos para projetos produtivos ou para o enfrentamento de crises cambiais, associados a problemas nos balanços de pagamentos (OLIVEIRA, 1998).

$\mathrm{Na}$ verdade, continua presente uma organização internacional imperialista, em grande medida, articulada por meio destas instituições globais dominadas eficazmente, tanto administrativamente quanto politicamente, por um punhado de nações-estado, os mais poderosos do mundo, principalmente os Estados Unidos (McNALLY, 1999).

Em linhas gerais, observa-se claramente que o novo papel das instituições "supranacionais" viabiliza a instrumentalização do novo processo integrativo do capital nos espaços mundiais, conformando um processo de centralização capitalista acelerada, ampliando a concentração do poder econômico e político num espaço restrito, qual seja, o Estado norte-americano. Desta forma, há uma subsunção, via coerção, do Leviatã estatal americano sobre os demais estados nacionais. Estas agências, na verdade, viabilizam a funcionalidade da nova configuração de poder interestatal.

Apesar das transformações do regime de acumulação verificadas nas últimas três décadas, não podemos afirmar que o capital e os mercados financeiros se tornam independentes do poder político. Observa-se que, segundo Chesnais, "a globalização entendida como a mundialização do capital não apaga a existência de Estados nacionais, nem as relações de dominação e de dependência entre eles. Ao contrário, acentuam os fatores de hierarquização entre países...". (CHESNAIS, 1997, p. 22). 
Em suma, tendo em vista a garantia da acumulação rentista, mediante a apropriação de armas mais poderosas, uma dialética "virtuosa" redefine as funções do Estado-Nação. Sendo assim, nota-se que o capital e os mercados financeiros não se desvinculam do poder político, uma vez que este continua sendo uma condição indispensável à multiplicação da lucratividade. Na verdade, não ocorre modificação do papel do poder político, mas sim de suas formas de atuação e proteção dos espaços nacionais econômicos garantidos para seus capitais. Este processo, nas últimas duas décadas, ampliou a concentração de poder econômico num espaço político restrito, enquanto a competição intercapitalista e interestatal tornou-se extremamente centralizada, o que levou ao aprofundamento da hierarquização entre estados nacionais.

\section{Conclusão}

Procurou-se ao longo deste trabalho, mediante uma trajetória analítica centrada nas leis de movimento e reprodução do capital, constatar que a trajetória do capitalismo contemporâneo, a partir do New Deal, foi marcada por uma primeira fase de ascensão prolongada e, reversamente, por uma outra, mais recente, de crise e estagnação, que perdura até os dias atuais.

Este movimento espelha a atuação estrutural das leis do capital, traduzidas em termos práticos, por um conjunto de padrões e formas que resultaram em determinados "modelos" de desenvolvimento.

O primeiro modelo analisado, conhecido como o padrão de acumulação dos anos dourados, representou o enfrentamento da queda da taxa de lucro, decorrente da crise de 1929, mediante um aparato que reduziu a autonomia da esfera financeira e colocou em primeiro plano o aparato estatal e uma intervenção econômica de caráter anticíclico. Já o segundo modelo, posto em prática num contexto de "convivência" com a crise, a esfera financeira recupera a hegemonia anterior ao New Deal, o que exige do Estado o desempenho de outras importantes funções.

Nos dois momentos experimentados pelo capitalismo, a função estatal foi a responsável pela transformação do endividamento em fundamento estrutural da reprodução capitalista, questão que, mais do que nunca, enfatiza quão decisivo o Estado foi e continua sendo para a manutenção da economia capitalista. Contudo, enquanto na primeira fase da onda longa iniciada no pós-Segunda Guerra o endividamento apresentou-se como um fator de inquestionável conteúdo dinâmico para a evolução da acumulação e do desenvolvi- 
mento capitalistas em bases virtuosas, no período de inflexão o endividamento assumiu contornos completamente distintos. Mesmo assim, por continuar funcionando de forma estrutural, em um contexto de crise, o endividamento transformou-se em um poderoso mecanismo de controle por parte das nações desenvolvidas sobre as mais atrasadas. Ao mesmo tempo transformou-se em uma barreira praticamente intransponível para exercício de uma política de desenvolvimento soberana por parte das nações dependentes rumo à superação da estagnação e da instabilidade.

Quanto ao plano da superestrutura política, poder-se-ia afirmar que a hegemonia do mundo capitalista, que no período em questão foi sempre exercida pelos EUA, foi transformada em função das mudanças ocorridas no padrão de acumulação. Sendo assim, enquanto nos anos dourados esta hegemonia foi exercida pelos EUA de forma coercitiva, mas com ênfase na persuasão, na fase de declínio a mesma passa a ser praticada quase exclusivamente com base na coerção.

Os EUA, que desde meados dos anos 1980 têm procurado reforçar sua posição de centro hegemônico, o fizeram em bases político-militares mais profundas e restritivas depois da derrocada da União Soviética e, mais recentemente, após o atentado de 11 de Setembro de 2001. Essa ação corresponde à imposição de um dispositivo imperialista inerente ao enfrentamento da crise.

Dados os elementos presentes na configuração da crise na qual o capitalismo está mergulhado, as condições objetivas de estagnação e turbulência apresentam elementos suficientes para a caracterização do quadro atual como de recessão global, ensejando fortes potenciais de agravamento ou explosão.

\section{Referências bibliográficas}

BALANCO, Paulo. As transformações do capitalismo: formulações teóricas para a composição de uma dialética da globalização. In: IV Encontro Nacional de Economia Política, Porto Alegre-RS, Anais (CD-ROM), 1 a 4 de junho de 1999.

BELLUZZO, Luiz Gonzaga. Finança global e ciclo de expansão. In: FIORI, José Luis (Orgs.). Estados e moedas no desenvolvimento das nações. Petrópolis, Vozes, 1999.

BRENNER, Robert. O boom e a bolha: os EUA na economia mundial. Rio de Janeiro, Record. 2003.

The economics of global turbulence: a special report on the world economy, 195098. London, New Left Review, n 229, May/June, 1998.

CHESNAIS, François. "Nova economia": uma conjuntura específica da potência hegemônica no contexto da mundialização do capital". Revista da Sociedade Brasileira de Economia Política, Rio de Janeiro, 7 Letras, $n^{\circ}$ 9, p. 53-85, dezembro de 2001.

A emergência de um regime de acumulação mundial predominantemente financeiro. In $\overline{\text { Praga - Estudos Marxistas, São Paulo, Hucitec, n }}$ 3, p. 19-46, 1997. 
CHESNAIS, François. A mundialização do capital. São Paulo, Xamã, 1996.

DUMÈNIL, Gerard; LÈVY, Dominique. Neoliberal dynamics: a new phase? Paris, Cepremap, 2004.

. Neoliberal dynamics - imperial dynamics (preliminary draft). In: III Colóquio Latinoamericano de Economistas Políticos, Buenos Aires, Anais, CD-ROM, 2003.

DUMĖNIL, Gerard; LEVY, Dominique. The three dynamics of the third volume of marx's capital. Paris, Cepremap, 1999.

GUTTMANN, Robert. As mutaçōes do capital financeiro. In: CHESNAIS, François (org). A mundializalação financeira: gênese, custos e riscos. São Paulo: Xamã, 1998.

HILFERDING, Rudolf. O capital financeiro. São Paulo, Abril Cultural, Os Economistas, 1985.

KATZ, Claudio. Ernest Mandel e a teoria das ondas longas. Revista da Sociedade Brasileira de Economia Política, Rio de Janeiro, 7 Letras, $n^{\circ} 7$, p. 74-103, dezembro de 2000

- Una recesión global entre guerras y rebeliones. In: II Colóquio Latino-Americano de Economistas Políticos. Anais (CD-ROM), Curitiba (PR), 28 a 31 de maio de 2002.

KLIMAN, Andrew J. Endividamento, crise econômica e a tendência de queda na taxa de lucro - uma perspectiva temporal. Revista da Sociedade Brasileira de Economia Política, Rio de Janeiro, 7 Letras, $n^{\circ}$ 6, p. 05-47, junho de 2000.

LENIN, Vladimir Ilich. Imperialismo: fase superior do capitalismo. São Paulo, Global, 1979. LICHTENSZTEJN, S.; BAER, M. Fundo Monetário Internacional e Bando Mundial: estratégias e políticas do poder financeiro. Editora brasiliense, São Paulo, 1987.

MANDEL, Ernest. O capitalismo tardio. São Paulo, Nova Cultural, Os economistas, 1985. MARX, Karl. O capital - crítica da economia política. São Paulo, Nova Cultural (Os Economistas), vols. IV e V, 1986.

MCNALLY, David. Turbulence in the world economy. Monthly Review, New York, Volume 51, number 2, June 1999.

MEYER, Victor. Articulação e organização internacional dos trabalhadores ante a globalização - um fenômeno emergente. Salvador, Escola de Administração/UFBA, Tese de Doutorado, 2000.

OLIVEIRA, Nelson. A conversăo obediente ao mandato imperial: reflexão sobre politicas impostas pelo Banco Mundial. Salvador, Cadernos do CEAS, nov/dez, n ${ }^{\circ} 178$, p. 21-44, 1998.

SALAMA, Pierre. Do produtivo ao financeiro e do financeiro ao produtivo na Ásia e na América Latina. Revista da Sociedade Brasileira de Economia Política, Rio de Janeiro, 7 Letras, $n^{\circ} 6$, p. 05-47, junho de 2000. 